\title{
ПАРАМЕТРЫ МИГРАЦИЙ ТИПИЧНЫХ ДЛЯ САМАРСКОЙ ОБЛАСТИ НАСЕКОМЫХ В СВЯЗИ С ПОИСКАМИ ИМИ ОПТИМАЛЬНЫХ УСЛОВИЙ ОБИТАНИЯ
}

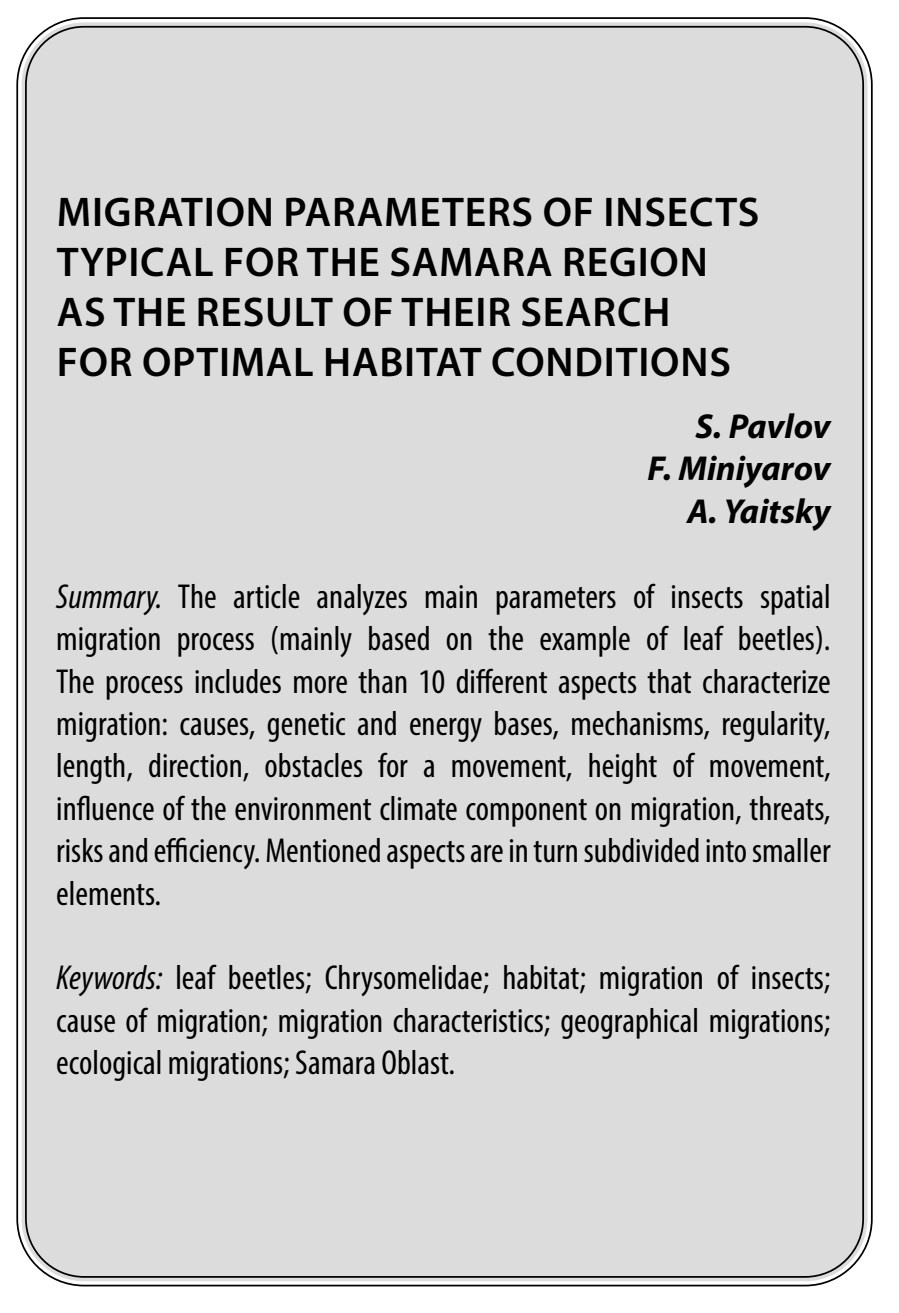

и зучение проблемы миграций насекомых интересно и весьма актуально. Миграции известны у чешуекрылых, стрекоз, саранчовых, перепончатокрылых, тлей, жесткокрылых [1]. Однако, единого мнения по поводу причин, типов и характеристик миграционных процессов до сих пор нет. Детально изучив особенности пространственных перемещений жуков-листоедов, их сроки и механизмы, и добавив к этому итоги наших наблюдений и результаты экспериментов над другими таксонами насекомых (наблюдение и мечение кокцинеллид и визуальное наблюдение за рядом видов чешуекрылых), мы предлагаем своё видение данной проблемы.

Отдельные аспекты миграционного поведения насекомых, анализ динамики их численности и обсужде-

\author{
Павлов Сергей Иванович \\ К.б.н., дочент, ФГБОУВО «Самарский \\ государственный социально-педагогический \\ университет» \\ pavlov@sgspu.ru \\ Минияров Фарит Талгатович \\ К.б.н., дочент, ФГБОУ ВО «Астраханский \\ государственный университет» \\ fminiyarov@mail.ru \\ Яицкий Андрей Степанович \\ Старший преподаватель, ФГБОУ ВО «Самарский \\ государственный социально-педагогический \\ университет» \\ yaitsky@sgspu.ru
}

Аннотация. В настоящей статье анализируются основные параметры процесса пространственной миграции насекомых (в первую очередь, жуков-листоедов - Chrysomelidae), включающего в себя более 10 различных аспектов, характеризующих миграции (причины; генетическая и энергетическая основы; механизмы; регулярность; протяженность; направленность; препятствия для перемещения; высота перемещений; влияние климатической компоненты среды на миграции; угрозы; риски; результативность), которые, в свою очередь, подразделяются на более мелкие элементы.

Ключевые слова: жуки-листоеды; Chrysomelidae; условия обитания; миграции насекомых; причины миграций; характеристики миграций; географические миграции; экологические миграции; Самарская область.

ние влияния климата на поведение насекомых рассматриваются в ряде известных публикаций [2-9], однако наша работа является попыткой обобщить уже опубликованную информацию и вновь приобретенную нами в процессе нативных наблюдений и полевых экспериментов.

\section{Цель исслеАования}

изучение особенностей миграций разных таксонов насекомых (главным образом, жуков-листоедов) и уточнение механизмов их расселения в пространстве (соотношение долей географических и экологических мигрантов; особенности подходов к классификации мигрантов по дальности расселения). 


\section{Материал и методика исслеАования}

Исследования закономерных и случайных миграций насекомых в Самарской области проводятся нами более 30 лет (с 1986 г.).

Регулярные экологические эксперименты по мечению проводились нами на 21 модельном участке площадью примерно от $50 \mathrm{~m}^{2}$ до $270 \mathrm{~m}^{2}$, занятом естественной растительностью, которая включает кормовые растения, предпочитаемые данными видами жуков-листоедов.

В экспериментах было задействовано 10 фоновых (для южного сектора Среднего Поволжья) видов жуков-листоедов: Donacia crassipes Fabricius, Oulema melanopus Linnaeus, Labidostomis pallidipennis Gebler, Timarcha tenebricosa Fabricius, Plagiodera versicolora Laicharting, Chrysomela populi Linnaeus, Leptinotarsa decemlineata Say, Gastrophysa polygoni Linnaeus, Galeruca tanaceti Linnaeus, Cassida rubiginosa Müller.

Имаго мы собирали вручную и отлавливали сачком; после их маркировки цифрами, выполненными белой краской на переднеспинке, выпускали в местах поимки. Всего было помечено 450 особей (по 45 - каждого вида). В дальнейшем (в среднем через 5 дней) меченых жуков вновь отлавливали и учитывали их размещение в пространстве. Из числа выпущенных насекомых, 293 $(65,1 \%)$ пойманы повторно 1 раз, 86 особей $(19,1 \%)$ найдены 2 раза, а 67 (14,9\%) - 3 раза.

В момент начала агрегации представителя кокцинеллид - Coccinella septempunctata Linnaeus - перед залеганием на зимовку, мы четырежды метили (описанным выше способом) по 50 особей из каждого скопления, и в течение последующих 2 дней искали меченые особи в направлении их перемещения в сторону возвышенных склонов.

Одновременно проводилась фото- и видеорегистрация эксперимента.

Параллельно оценивались сопутствующие экологические параметры среды.

Латинские наименования видов жуков-листоедов в статье приводятся по работе Ю.М. Зайцева, Л.Н. Медведева [10].

\section{Результаты исслеАования и их обсу»}

По мнению М.С. Гилярова (цит. по: [11]), «один из двух возможных путей успешного выживания вида - миграция в другие условия обитания». В настоящем исследо- вании нас, в первую очередь, интересует именно эта особенность биологии данных видов.

По нашему мнению, под термином «миграция» следует понимать закономерные перемещения животных, выработанные в ходе филогенеза, реализуемые в конкретное время, и, по большей части, по закономерным направлениям.

С точки зрения М. Коха, все насекомые делятся на 2 группы [12]:

1. близко расселяющиеся;

2. истинные мигранты.

По нашему мнению, близко расселяющихся насекомых уместно называть экологическими мигрантами, а истинных (дальних) мигрантов - географическими. По этой причине логично выделить 2 типа одноименных миграций: экологические и географические.

Экологические мигранты перемещаются, регулярно или эпизодически, но внутри своего же генерационного ареала. Мы отмечали сезоны, когда динамика популяций была стабильной, т.е. реального расселения не наблюдалось.

Для географических мигрантов характерны следующие признаки:

1. осуществляют дальние перемещения ежегодно;

2. покидают область генерации, куда потом возвращаются вновь;

3. способны за короткое время преодолевать большие расстояния;

4. не могут зимовать в средних широтах;

5. перелеты их ориентированы только с севера на юг (и обратно).

\section{Характеристики миграций}

Причины миграций. Предполагается, что происхождение географических (дальних) миграций следует связывать с изменениями климата в недалеком геологическом прошлом планеты [13].

Состояния среды, корректирующие географические миграции:

1. сезонное потепление среды;

2. сезонное похолодание среды.

Состояния среды, корректирующие экологические миграции:

1. расселение с мест зимовки;

2. уход на зимовку;

3. дефицит и поиски корма;

4. репродуктивные агрегации; 
5. влияние эффекта массы (потребность насекомых рассредотачиваться в пространстве при избыточной плотности в «очагах скопления»).

Нами отмечены частые массовые кочевки особей отдельных популяций листоедов в поисках корма на расстояния 30-70 м (за границы прежних местообитаний).

Kроме Chrysomelidae, мы наблюдали предзимовочные перемещения Coccinellidae в Жигулёвских горах на 300-450 м в сторону возвышенных склонов и карстовых поноров. В результате в каждой меченой группе (численностью в 50 особей) кокцинеллид, мы отмечали следующую нисходящую закономерность:

- 1-й стометровый участок: 8-11 найденных меченых кокцинеллид (разброс объясняется разным количеством найденных меченых особей в результате каждого последующего акта маркировки);

- 2-й стометровый участок: 5-6 особей (из 50);

- 3-й стометровый участок: 2-3 особей (из 50);

- 4-й стометровый участок: 0,6-0,9 особей (из 50).

Подобная особенность распределения жуков объясняется целым рядом причин (расстоянием до будущих зимовочных «затаек», влиянием хищников-энтомофагов, бескормицей, сильным ветром или осадками, а, главное - рассредоточением меченых особей среди основной массы немеченых жуков).

Генетическая основа миграций. Установлено, что географические мигранты формируются, в первую очередь, в перенаселенных популяциях, а экологические мигранты - в популяциях с довольно низкой плотностью [14].

Энергетическая основа миграциий. Насекомые, географические мигранты (в особенности, бабочки и тли), имеют больше жировых запасов, чем экологические мигранты, но меньшее число заканчивающих развитие эмбрионов [14].

\section{Механизмы миграций}

\section{1. Пешие кочевки (переползание):}

а) под влиянием абиотических факторов: при движении к свету и от него; при поисках температурного оптимума; из области повышенной влажности воздуха; из зоны раздражающего ветрового потока;

б) под влиянием биотических факторов: поиски индивидом кормового растения или брачного партнера; внедрение внутрь скопления (действие «эффекта группы» - при спаривании или уходе на зимовку); наружу из очага скопления (дей- ствие «эффекта массы» - при расселении, поисках корма и т.п.) [15].

2. Воздушные перемещения (перелёты):

а) закономерные: при рассредоточении в результате «эффекта массы» в пространстве;

б) случайные (дисперсии): под действием ветра (в момент дрейфа во время полёта).

3. Водные перемещения (переплывание). Все жуки-листоеды, кроме радужниц, избегают воды, но случается, что они непроизвольно попадают в воду, и в этом случае расселяются пассивно:

а) в результате непосредственного падения в воду;

б) в результате попадания в воду во время ухода от подтопления на более высокий субстрат;

в) на плавучей основе - «паводковом шламе», ветках, стволах деревьев-топляков [11].

\section{Регулярность} миграций

1. регулярные: 2 раза в год - весной на север, в конце лета на юг;

2. нерегулярные: в любом направлении, иногда несколько раз за вегетационный сезон.

\section{Протяженность} миграций

1. дальние - на расстояние в 1 тыс. км и более (некоторые чешуекрылые и прямокрылые);

2. ближние - на расстояние от нескольких десятков до нескольких сотен метров (прочие таксоны насекомых). Установлено, что радиус репродуктивных перемещений за сезон значительно превышает даже радиус кормовых кочевок; так, по данным В.М.Соломатина, листоед Chrysochloa cacaliae Schrnk в первом случае преодолевает 2-3 км за сезон, а во втором только 1,0-1,1 км (а совокупная протяженность его кочевок может достигать от 3,0 до 4,1 км за сезон) [16].

В то же время, данная классификация у экологических мигрантов осложняется особенностями влияния сезонных или суточных параметров среды:

1) сезонные (горизонтальные) перемещения:

а) весна - осень (дальние миграции);

б) лето: 1-я половина - 2-я половина (локальные миграции);

в) лето: 2-я половина (локальные миграции).

2) суточные (вертикальные) перемещения: 
а) утро (выход гелиофилов в верхнюю часть кроны) день (максимум их активности) - вечер (их уход на ночевку);

б) день - сумерки (активность умброфилов);

в) день - ночь (активность умброфилов).

Из общего списка энтомофауны на долю географических мигрантов приходится, по нашей оценке, около 34\%, а экологических мигрантов - 66\%.

\section{Направленность миграций}

1. закономерные (направление с севера на юг и обратно): вектор полетов отдельных особей хорошо летающих насекомых (в первую очередь, бабочек) близок к единому «коридору» географической сезонной миграции, который практически неизменен в течение светового дня и мало варьирует за вегетационный сезон;

2. дисперсныле (случайные) - в любую сторону для реализации тактической программы (поисков брачного партнера, корма, укрытия).

Препятствия для перемещения. Хорошо летающие бабочки преодолевают естественные и искусственные древостои [1], не меняя своего курса следования и перелетая их сверху. По нашим наблюдениям, для многих жуков-листоедов (удельный вес которых значительно больше, чем у бабочек одинакового с ними размера), лес (высокий и частый вертикальный барьер), обширное водное зеркало (горизонтальный барьер) - являются серьезными препятствиями в ходе их перемещения.

Высота перемещений:

1. значительная - от 25 до 150-200 м;

2. в приземном слое - от 1,5-2,0 до 8-12 м.

Разумеется, чёткую границу провести затруднительно, поскольку при сильном встречном или боковом ветре хорошо и высоко летающие бабочки стремятся уйти из его потока, опускаясь ниже, а при высокой влажности воздуха или тумане низко летающие насекомые стремятся подняться выше своего нормального «потолка» полёта в зону более сухого воздуха.

Влияние климатической компоненты среды. Возможность и качество миграций жестко корректируется климатом:

1. Температурой воздуха (по нашей оценке, оптимум заключен в интервале от $+20^{\circ} \mathrm{C}$ до $+27^{\circ} \mathrm{C}$ ).

2. Интенсивностью солнечного излучения. По наблюдениям Ф.С. Кохманюка [17], колорадский жук мигрирует в ясную погоду. Это подтверждается и нашими наблюдениями, согласно которым большинство видов насекомых (и не только жу- ков-листоедов) наиболее активны и мобильны в ясную погоду.

3. Ветром. Нами замечено, что во время дальних перелетов бабочки с высокой точностью «выдерживают» постоянный вектор движения, несмотря на встречный или боковой довольно сильный ветер; а саранчовые, тли и колорадский жук, в основном, «дрейфуют» в шлейфе ветровых потоков. Ряд наблюдений Ф.С. Кохманюка за колорадским жуком доказывают устойчивую склонность вида расселяться по направлению ветра [17].

4. Осадками. Даже при слабом дожде полёты мигрантов прекращаются; при облачности от 30\% до 45\% пролёт идёт с малой интенсивностью, а при более чем $45 \%$ пролёт не наблюдается.

Угрозы и риски, сопутствующие миграциям. Внезапные похолодания, тепловой удар, ливневые и затяжные дожди, сильный, резко меняющий направление ветер, насекомоядные птицы, рукокрылые, жажда и бескормица - являются основными негативными факторами. Есть данные о средней ежедневной гибели мигрирующих насекомых: из каждых $100 \%$ учтенных особей на 2-й день сохранялось лишь 33 особи, на 3-й - 21, на 4-й - 16, на 5-й - 10, на 6-й - 3,5, на 7-й - 2,2 [18].

Нами выявлен высокий уровень консерватизма (стенобионтности) жуков в приуроченности к биотопам. Только 28 (т.е. чуть больше 6\%) особей 4-х видов были найдены за пределами мест выпуска.

Результативность (успех) миграц̧ий. В штилевую погоду перелёт жука-листоеда на 300 м занимает около 15 мин. (успешная результативность бо́льших расстояний перемещения по воздуху для жуков-листоедов имеет уже, на наш взгляд, весьма случайный характер). Установлено, что самцы-мигранты более активны и мобильны (поскольку помимо только «программы расселения» им приходится выполнять параллельную «программу поиска брачного партнёра», что требует от них более высокой оперативности).

\section{Зак^ючение}

В результате наших нативных наблюдений и полевых экспериментов выявлены основные составляющие процесса пространственной миграции насекомых (главным образом, Coleoptera: Chrysomelidae, и в некоторой степени - Coccinellidae), включающего в себя более 10 различных определяющих аспектов (причины; генетическая и энергетическая основы; механизмы; регулярность; протяженность; направленность; препятствия для перемещения; высота перемещений; влияние климатической компоненты среды на миграции; угрозы; риски; результативность). 


\section{ЛИТЕРАТУРА}

1. Smithers C. N. Insect migration // The Australian Museum Magazine. 1961. Vol. 13, № 11. P. 350-353.

2. Голубев А. В. Миграции в динамике численности популяций фитофагов // Вестник Московского государственного университета леса - Лесной вестник. 2003. № 2. C. 83-86.

3. Исаев А.С., Березовская Ф.С., Давыдова Н. В., Карев Г.П., Хлебопрос Р. Г. Волны миграции и пространственная динамика насекомых-фитофагов // Сибирский экологический журнал. 1999. Т. 6, № 4. С. 45-53.

4. Борисов С. Н. Особенности осенних миграций стрекоз (Odonata) на перевале Чокпак в западном Тянь-Шане: видимые и реальные масштабы перелётов // Евразиатский энтомологический журнал. 2010. Т. 9, № 1. С. 7-12.

5. Воробьева О. В. Анализ распределения уязвимых энтомокомплексов по территории Белгородской области // Научные ведомости Белгородского государственного университета. Серия: Естественные науки. 2007. № 5 (36). С. 54-60.

6. Кузнецова В.В., Пальникова Е. Н. Факторы динамики численности боярышницы (Арoria crataegi L.) в пригородных насаждениях г. Красноярска // Известия Санкт-Петербургской лесотехнической академии. 2014. № 207. С. 4-9.

7. Ключко Е.М., Ключко 3. Ф. Электронные информационные системы для мониторинга популяций и миграций насекомых // Biotechnologia Acta. 2018. T. 11, № 5. C. 5-25.

8. Соколов Л. В. Климат в жизни растений и животных. СПб.: Тесса, 2010. 343 с.

9. Шелабина Т.А., Берим М. Н. Динамика численности и видовой состав тлей на посадках семенного картофеля в Ленинградской области // Аграрная Россия. 2020. № 4. C. 3-7.

10. Зайцев Ю.М., Медведев Л. Н. Личинки жуков-листоедов России. М.: Товарищество науч. изд. КМК, 2009. 246 с.

11. Павлов С.И., Яицкий А. С. Фауна жуков-листоедов (Coleoptera, Chrysomelidae) изолированных волжских островов и механизмы их вторичного заселения // Самарский научный вестник. 2018. Т. 7, № 4 (25). С. 97-103.

12. Koch M. Zur Gruppeneinteilung der Wanderfalter // Wiener Entomologische Gesellschaft. 1964. Vol. 75, № 9-10. P. 131-134.

13. Gaskin D. E. Comments on the nature and origins migrations of Lepidoptera to Bermuda // The Journal of the Lepidopterists' Society. 1994. Vol. 48, № 4. P. 388-393.

14. Kidd N.A.C., Cleaver A. M. The relationship between pre-flight reproduction and migratory urge in alatae of Aphis fabae Scopoli (Hemiptera: Aphididae) // Bulletin of Entomological Research. 1984. Vol. 74, № 3. P. 517-527.

15. Павлов С.И., Яицкий А. С. Динамика плотности жуков-листоедов (Coleoptera, Chrysomelidae) в агроценозах злаковых культур Самарской области // Самарский научный вестник. 2018. Т. 7, № 2 (23). С. 94-102.

16. Соломатин В. М. Экологическая дифференциация и система скрещиваний у Chrysochloa cacaliae Schrnk. (Coleoptera, Chrysomelidae) на Kapпатах: дис. ... канд. биол. наук: 03.00.15. М., 1977. $140 \mathrm{c}$.

17. Кохманюк Ф.С. 0 миграциях имаго колорадского жука (Leptinotarsa decemlineata Say) // Механизмы поведения животных: мат-лы 3-й всесоюз. конф. по поведению животных. Т. 1. М.: Наука, 1983. С. 203-204.

18. Sanders C. I. Local dispersal of male spruce budworm (Lepidoptera: Tortricidae) moths determined by mark, release and recapture // Canadian Entomologist. 1983. Vol. 115, № 9. P. 1065-1070.

(с) Павлов Сергей Иванович ( pavlov@sgspu.ru),

Минияров Фарит Талгатович ( fminiyarov@mail.ru), Яицкий Андрей Степанович ( yaitsky@sgspu.ru).

Журнал «Современная наука: актуальные проблемы теории и практики» 